S. Parnovsky, Dr. Sci., Prof.

Astronomical Observatory of National Taras Shevchenko University of Kyiv

\title{
AN IMPACT OF NEARBY ATTRACTORS ON THE COLLECTIVE PECULIAR MOTION OF GALAXIES
}

We study the impact of individual attractors on the multipole model of the collective motion of galaxies. Equations obtained provide a theoretical possibility to estimate masses and locations of attractors together with the parameters of the multipole model. Unfortunately, this is not possible on the state-of-the-art level of estimation of galaxy' peculiar velocities.

С. Парновский, д-р. физ.-мат. наук, проф.

Астрономическая Обсерватория Киевского национального университета имени Тараса Шевченко

\section{ВЛИЯНИЕ БЛИЗКИХ АТРАКТОРОВ НА КРУПНОМАСШТАБНОЕ КОЛЛЕКТИВНОЕ ПЕКУЛЯРНОЕ ДВИЖЕНИЕ ГАЛАКТИК}

Рассчитано влияние отдельных атракторов на мультипольную модель крупномасштабного коллективного движения галактик. Выведены формулы, теоретически позволяющие получить массы и положения атракторов вместе с параметрами мультипольной модели. Но для современного уровня точности оценки пекулярных скоростей галактик это невозможно.

УдК 524.7

О. Александров, канд. фіз.-мат. наук, старш. наук. співроб. В. Жданов, д-р фіз.-мат. наук, проф.

Астрономічна обсерваторія Київського національного університету імені Тараса Шевченка

\section{ЧАСОВА ЗАТРИМКА КРИТИЧНИХ ЗОБРАЖЕНЬ В ОКОЛІ КАСПОВОЇ ТОЧКИ ГРАВІТАЦІЙНО-ЛІНЗОВОЇ СИСТЕМИ}

\begin{abstract}
Отримано наближені формули для часової затримки критичних зображень точкового джерела, що знаходиться поблизу каспової точки каустики. Ми обговорюємо формули нульового, першого і другого порядків за степенями параметра, який задає близькість джерела до каустики. Ці формули пов'язують час затримки з характеристиками лінзового потенціалу. Формула нульового наближення була отримана в роботі Конгдона, Кітона i Нордгрена (MNRAS, 2008). Для загального потенціалу ми знайшли до неї поправку першого порядку. У випадку потенціалу, симетричного відносно осі каспу, ця поправка тотожно дорівнює нулю. Для цього випадку ми отримали поправку другого порядку. Знайдені співвідношення проілюстровані на простому модельному прикладі.
\end{abstract}

При так званому сильному гравітаційному лінзуванні (макролінзуванні) спостерігають декілька зображень одного й того самого джерела електромагнітного випромінювання. Зазвичай джерелом є квазар, а лінзою слугує більш близька галактика або скупчення галактик. Коли джерело можна вважати точковим, спостережуваними характеристиками гравітаційно-лінзової системи (ГЛС) є червоні зміщення лінзи і джерела, взаємні положення зображень і відношення потоків від різних зображень. Крім того, власна змінність джерела дозволяє визначити відносну часову затримку між різними зображеннями, яка виникає внаслідок того, що ці зображення формуються променями, що поширюється від джерела до спостерігача різними шляхами. Часова затримка залежить від відстаней до лінзи і до джерела, геометрії ГЛС; вона також є чутливою до космологічної моделі. Ці спостережувані характеристики слугують основою для моделювання ГЛС i, отже, для визначення її фізичних параметрів, таких, наприклад, як розподіл маси в лінзі. Виявляється, що для деяких ГЛС неможливо за допомогою гладкого розподілу маси задовольнити спостережуваним значенням потоків або затримок. Це так звані аномальні потоки (затримки), які розглядаються як свідчення існування значних локальних мас іноді в самій галактиці, іноді поруч із нею [1].

Серед спостережуваних характеристик ГЛС особлива роль належить часу затримки, оскільки це розмірна величина, яка дозволяє оцінити просторовий масштаб. Очікують, що у найближче десятиліття кількість ГЛС з визначеними затримками буде вимірюватися тисячами, що дозволить ефективно застосовувати статистичні методи, з чим пов'язують сподівання стосовно досліджень темної матерії і космології [2-4].

Найбільш яскраво явище гравітаційного лінзування проявляє себе, коли джерело знаходиться поблизу каустики ГЛС, при перетині якої точковим джерелом блиск деяких його зображень формально стає нескінченим. Такі зображення ми називаємо критичними. Щоби змоделювати властивості критичних зображень достатньо задати потрібну кількість похідних гравітаційно-лінзового потенціалу у відповідній критичній точці. В роботі [5] ми найшли і дослідили формули для часової затримки критичних зображень поблизу регулярної точки каустики (особливості лінзового відображення типу "складка"). В цій роботі ми досліджуємо аналогічні питання для випадку, коли точкове джерело знаходиться поблизу каспу каустики (особливість типу "зборка"). Ми застосовуємо метод наближень за степенями параметра близькості до каустики. Для часу затримки у нульовому наближенні ми отримали формулу, що еквівалентна знайденій в [6]. Далі для загального каспу ми знайшли поправку першого порядку, і для симетричного каспу поправку другого порядку. В основі побудов лежать формули для координат критичних зображень, отримані нами в $[7,8]$. Аби проілюструвати знайдені співвідношення ми розглянули час затримки критичних зображень точкового джерела, що знаходиться на осі лінзи Чанг-Рефсдала [9, 10].

1. Вихідні положення теорії гравітаційного лінзування

Ми використовуємо ті самі позначення, що і в попередніх роботах. Зокрема в роботі [5] докладно приведені всі необхідні вихідні співвідношення, тому тут ми обмежуємося дуже стислим викладенням. Рівняння гравітаційної лінзи має такий вид (див. напр. [6, 10]):

$$
\mathbf{y}=\mathbf{x}-\boldsymbol{\alpha}(\mathbf{x}) .
$$

Тут вектори $\mathbf{y}$ i $\mathbf{x}$ - кутові положення точкового джерела і його зображення на небесній сфері в одиницях кута Ейнштейна $\theta_{0}$. 3 іншого боку $\mathbf{x}$ можна інтерпретувати як вектор у площині лінзи, виміряний у радіусах Ейнштейна $R_{E}=D_{L} \theta_{0}, \mathbf{y}-$ вектор в площині джерела в одиницях $D_{S} \theta_{0}$. Кут відхилення $\boldsymbol{\alpha}(\mathbf{x})$ визначається фрормулою 


$$
\mathbf{\alpha}(\mathbf{x})=\frac{1}{\pi} \iint k\left(\mathbf{x}^{\prime}\right) \frac{\mathbf{x}-\mathbf{x}^{\prime}}{\left|\mathbf{x}-\mathbf{x}^{\prime}\right|^{2}} d^{2} \mathbf{x}^{\prime},
$$

де $k(\mathbf{x})$ - нормована поверхнева густина маси в лінзі.

Поле $\boldsymbol{\alpha}(\mathbf{x}) €$ потенціальним: $\boldsymbol{\alpha}=\nabla \Psi$, де

$$
\Psi(\mathbf{x})=\frac{1}{\pi} \iint k\left(\mathbf{x}^{\prime}\right) \ln \left(\left|\mathbf{x}-\mathbf{x}^{\prime}\right|\right) d^{2} \mathbf{x}^{\prime}
$$

3 рівняння (3) випливає, що

$$
\Delta \Psi=2 k
$$

Отже, властивості ГЛС у нормованих змінних визначаються лінзовим потенціалом $\Psi(\mathbf{x})$.

Час поширення світлового сигналу від джерела до спостерігача у присутності гравітаційної лінзи відрізняється від такого ж у вільному просторі на величину, яка з точністю до адитивної константи дається формулою [1, 10]:

$$
T(\mathbf{x}, \mathbf{y})=\tau_{0}\left[\frac{1}{2}|\mathbf{y}-\mathbf{x}|^{2}-\Psi(\mathbf{x})\right] .
$$

Тут $\tau_{0}=\frac{1+z_{L}}{c} \frac{D_{L} D_{S}}{D_{L S}} \theta_{0}^{2}, z_{L}$ - параметр червоного зміщення лінзи, $D_{L}, D_{S}, D_{L S}-$ відповідно відстані (за кутовим діаметром) від спостерігача до лінзи, від спостерігача до джерела та від лінзи до джерела. Величина $\tau_{0}$, яка має розмірність часу, варіює для різних ГлС у широкому діапазоні. Але для оцінки зазначимо, що за вибіркою з 19 ГлС, для яких наведені данні в роботі [1], середнє значення $\left\langle\tau_{0}\right\rangle \approx 115$ і медіанне значення $\tau_{0 \text { теd }} \approx 80$ днів.

Для отримання часу відносної затримки між двома зображеннями достатньо знайти різницю двох відповідних виразів (5). Для величини нормованого часу затримки введемо таке позначення $T_{N}=T(\mathbf{x}, \mathbf{y}) / \tau_{0}$. Скориставшись рівнянням (1) та формулою для кута відхилення, отримуємо вираз для часу затримки як функції координат зображення

$$
T_{N}(\mathbf{x})=\frac{1}{2}(\nabla \Psi)^{2}-\Psi
$$

Рівняння (1) можна розглядати як відображення $\mathbf{y}(\mathbf{x})$ площини зображень на площину джерел. У загальному випадку одному положенню $\mathbf{y}$ точкового джерела відповідає декілька зображень $\mathbf{x}^{(i)}$ - розв'язків рівняння (1). Коефіцієнт підсилення $i$-го зображення визначається через якобіан лінзового відображення [10]:

$$
K^{(i)}=\left.|J|^{-1}\right|_{\mathbf{x}^{(i)}}, \quad J(\mathbf{x})=\frac{D\left(y_{1}, y_{2}\right)}{D\left(x_{1}, x_{2}\right)} .
$$

Точки $\mathbf{x}$, в яких $J(\mathbf{x})=0$ називають критичними, а відповідні їм точки площини джерел - каустичними. Добре відомо, що стійкі критичні точки гладких відображень двовимірних многовидів бувають лише двох видів: складки і зборки. При цьому складки утворюють гладку криву, а зборки - її точки повертання. Каустичні криві відокремлюють області площини джерел, які мають різну кількість зображень. Коли точкове джерело наближається до складки з того боку, якому відповідає більша кількість зображень, два зображення прямують до відповідної критичної точки, їх коефіцієнти підсилення зростають до нескінченності. А після того, як джерело перетне каустику, ці два зображення зникають. Такі зображення називають критичними. Якщо ж шлях джерела перетинає каустику в точці зборки, то вже три критичних зображення зустрічаються у відповідній критичній точці, їх підсилення також стають нескінченними, але після перетину джерелом каустики одне із цих зображень виживає. В теорії гравітаційного лінзування зборки називають каспами.

\section{2. Перехід до локальних координат у околі каспу}

При розгляді околу критичної точки $\mathbf{x}_{0}$ початок координат на площині зображень переносять в цю точку, а початок координат площини джерел у відповідну точку каустики $\mathbf{y}_{0}=\mathbf{y}\left(\mathbf{x}_{0}\right)$. Перейдемо до локальних координат $\mathbf{X}=\mathbf{x}-\mathbf{x}_{0}$ і $\mathbf{Y}=\mathbf{y}-\mathbf{y}_{0}$ в рівнянні лінзи:

Тут $\Psi_{L}(\mathbf{X})=\Psi(\mathbf{x})-\Psi\left(\mathbf{x}_{0}\right)-\nabla \Psi\left(\mathbf{x}_{0}\right)\left(\mathbf{x}-\mathbf{x}_{0}\right)$.

$$
\mathbf{Y}=\mathbf{X}-\nabla \Psi_{L}(\mathbf{X})
$$

Для різниці $\Delta T\left(\mathbf{x}, \mathbf{x}_{0}\right)=T_{N}(\mathbf{x})-T_{N}\left(\mathbf{x}_{0}\right)$ часів поширення світла, що відповідають двом точкам площини зображень, застосовуючи формули (6) і (8), отримуємо

$$
\Delta T\left(\mathbf{x}, \mathbf{x}_{0}\right)=\Delta_{1} T+\Delta_{L} T
$$

Тут $\Delta_{L} T\left(\mathbf{x}, \mathbf{x}_{0}\right)=\frac{1}{2}\left(\nabla \Psi_{L}\right)^{2}-\Psi_{L}--$ величина, що визначається такою самою формулою як (6), але за потенціалом $\Psi_{L}$; $\Delta_{1} T=-\nabla \Psi\left(\mathbf{x}_{0}\right) \cdot \mathbf{Y}$. Величину $\Delta_{L} T$ будемо називати локальним часом затримки.

Формула (9) дає затримку зображення в точці $\mathbf{x}$ відносно зображення в опорній точці $\mathbf{x}_{0}$. Часова затримка $\Delta T(1,2)$ між зображеннями в точках $\mathbf{x}_{1}$ і $\mathbf{x}_{2}$ дорівнює різниці $\Delta T\left(\mathbf{x}_{1}, \mathbf{x}_{0}\right)-\Delta T\left(\mathbf{x}_{2}, \mathbf{x}_{0}\right)$. Якщо точки $\mathbf{x}_{1}$ і $\mathbf{x}_{2}$ суть два 
зображення однієї точки (що має локальні координати $\mathbf{Y}$ ), то доданки $\Delta_{1} T$ в виразі для відносної затримки скорочуються. При цьому затримка $\Delta T(1,2)=\Delta_{L} T\left(\mathbf{x}_{1}, \mathbf{x}_{0}\right)-\Delta_{L} T\left(\mathbf{x}_{2}, \mathbf{x}_{0}\right)$ визначається лише доданками $\Delta_{L} T$.

Осі локальної системи координат в критичній точці спрямовують вздовж власних векторів матриці Якобі лінзового відображення. Точніше у випадку складки першу координатну вісь на площині джерел обираємо дотичною до критичної кривої, а у випадку каспу - вздовж спільної напівдотичної двох гілок каустики, що сходяться у точці каспу. Такій вибір забезпечує певну структуру квадратичних доданків в розкладі локального потенціалу.

3 потрібною точністю цей розклад записується так:

$$
\begin{gathered}
\Psi_{L}=+\frac{1}{2}(1-2 \sigma) X_{1}^{2}+\frac{1}{2} X_{2}^{2}-\frac{1}{3} a_{1} X_{1}^{3}-b_{2} X_{1}^{2} X_{2}+a_{2} X_{1} X_{2}^{2}+\frac{1}{3} b_{1} X_{2}^{3}- \\
-\frac{1}{4} c_{3} X_{1}^{4}-d_{2} X_{1}^{3} X_{2}+\frac{3}{2} c_{1} X_{1}^{2} X_{2}^{2}+d_{1} X_{1} X_{2}^{3}-\frac{1}{4} c_{2} X_{2}^{4}-\frac{1}{5} g_{3} X_{1}^{5}- \\
-f_{2} X_{1}^{4} X_{2}+2 g_{2} X_{1}^{3} X_{2}^{2}+2 f_{1} X_{1}^{2} X_{2}^{3}-g_{1} X_{1} X_{2}^{4}-\frac{1}{5} f_{3} X_{2}^{5}-\frac{1}{6} h X_{2}^{6}+\ldots
\end{gathered}
$$

Де введені такі скорочені позначення:

$$
\begin{aligned}
& a_{1}=-\frac{1}{2} \Psi_{, 111} ; \quad a_{2}=\frac{1}{2} \Psi_{r_{122}} ; \quad b_{1}=\frac{1}{2} \Psi_{, 222} ; \quad b_{2}=-\frac{1}{2} \Psi_{, 112} ; \quad c_{1}=\frac{1}{6} \Psi_{, 1122} ; \\
& c_{2}=-\frac{1}{6} \Psi_{, 2222} ; \quad c_{3}=-\frac{1}{6} \Psi_{, 1111} ; \quad d_{1}=\frac{1}{6} \Psi_{, 1222} ; \quad d_{2}=-\frac{1}{6} \Psi_{, 1112} \text {; } \\
& g_{1}=-\frac{1}{24} \Psi_{,_{12222}} ; g_{2}=\frac{1}{24} \Psi_{,_{11122}} ; g_{3}=-\frac{1}{24} \Psi_{{ }_{11111}} ; f_{1}=\frac{1}{24} \Psi_{,_{11222}} \text {; } \\
& f_{2}=-\frac{1}{24} \Psi_{, 11112} ; \quad f_{3}=-\frac{1}{24} \Psi_{, 22222} ; \quad h=-\frac{1}{120} \Psi_{, 222222} ; \quad \sigma=1-k_{0} .
\end{aligned}
$$

Позначення введені так, що при постійному $k=k(\mathbf{0}) a_{1}=a_{2}, b_{1}=b_{2}, c_{1}=c_{2}=c_{3}, d_{1}=d_{2}, g_{1}=g_{2}=g_{3}, f_{1}=f_{2}=f_{3}$. Формулювання відповідного розкладу рівняння (8) не містить жодних труднощів, і ми його не наводимо.

Умова того, що точка $\mathbf{x}=0 €$ каспом - це $b_{1}=0$. Параметр близькості у цьому разі вводиться такими співвідношеннями: $Y_{1}=t^{2} \tilde{y}_{1}, Y_{2}=t^{3} \tilde{y}_{2}, \tilde{y}_{i}=$ const .; координати критичних зображень шукаються у вигляді $[7,8]$

$$
x_{1}=t^{2}\left(x_{10}+x_{11} t+x_{12} t^{2}\right), \quad x_{2}=t\left(x_{20}+x_{21} t+x_{22} t^{2}\right)
$$

Допоміжний параметр $t$ слугує для більш простого врахування доданків різних наближень; у кінцевих фрормулах треба покласти $t=1$.

В основі побудови розв'язків лежить рівняння третього порядку для $x_{20}$ :

$$
C x_{20}^{3}-a_{2} \tilde{y}_{1} x_{20}-\sigma \tilde{y}_{2}=0
$$

де $C=c_{2} \sigma-a_{2}^{2}$. Рівняння (13) має один чи три дійсних корені в залежності від знака виразу $Q=\frac{\tilde{y}_{2}^{2} \sigma^{2}}{4 C^{2}}-\frac{a_{2}^{3} \tilde{y}_{1}^{3}}{27 C^{3}}$. Один дійсний корінь, коли $Q>0$; три дійсних кореня, коли $Q \leq 0$ (два з них збігаються, коли $Q=0$ ). Явні вирази розв'язків рівняння (13), тобто нульове наближення для другої координати зображень $x_{20}$, даються відомими фрормулами Кардано. Всі інші характеристики зображень мають вид дрібно-раціональних функцій змінних $\tilde{y}_{i}$ і $x_{20}$. При цьому внаслідок рівняння (13) всі степені $x_{20}$ вище другого виражаються через нижчі.

Нульове наближення для першої координати зображень дається формулою

$$
x_{10}=\frac{1}{2 \sigma}\left(\tilde{y}_{1}+a_{2} x_{20}^{2}\right) .
$$

Загальний вигляд поправок першого порядку $x_{11}$ і $x_{21}$ знайдено в роботі [7]. Характерна особливість розв'язків в околі каспу полягає в тому, що, коли потенціал (10) $€$ симетричним відносно осі $x_{1}$, то всі поправки першого порядку дорівнюють нулю (разом з параметрами $b_{2}, d_{1}, f_{3}$ ). У випадку симетричного каспу в [8] були знайдені вирази для поправок другого порядку $x_{12}$ i $x_{22}$.

3. Часова затримка зображень в околі каспу

3 формули (6), в яку підставлено вираз (10) як потенціал і розклади (12) для координат, знаходимо, що розклад локального часу затримки за степенями параметра $t$ з потрібною точністю можна подати у вигляді

$$
\Delta_{L} T=t^{4}\left(\Delta_{L 0} T+t \Delta_{L 1} T+t^{2} \Delta_{L 2} T\right)
$$

Для нульової (головної) компоненти нами знайдено

$$
\Delta_{L 0} T=-\frac{a_{2} \tilde{y}_{1} x_{20}^{2}+3 \sigma \tilde{y}_{2} x_{20}+(1-2 \sigma) \tilde{y}_{1}^{2}}{4 \sigma}
$$

Ця формула еквівалентна співвідношенню (45) роботи [6]. 
Поправка першого порядку до локального часу затримки в околі каспу загального виду дається таким виразом:

$$
\Delta_{L 1} T=\frac{5 C P_{1} \cdot \tilde{y}_{1} \tilde{y}_{2} x_{20}^{2}+\sigma\left(2 a_{2} P_{2} \cdot \tilde{y}_{1}^{3}+3 C P_{3} \cdot \tilde{y}_{2}^{2}\right) x_{20}+P_{4} \cdot \tilde{y}_{1}^{2} \tilde{y}_{2}}{20 C^{2} E \sigma} \text {. }
$$

Тут

$$
\begin{gathered}
E=a_{2} \tilde{y}_{1}-3 c x_{20}^{2} ; \\
P_{1}=b_{2} a_{2}^{3}+4 \sigma d_{1} a_{2}^{2}-\left(6 \sigma b_{2} c_{2}+4 \sigma^{2} f_{3}\right) a_{2}+6 \sigma^{2} c_{2} d_{1}, \\
P_{2}=-4 f_{3} a_{2}^{3}+10 c_{2} d_{1} a_{2}^{2}-5 b_{2} c_{2}^{2} a_{2}, \\
P_{3}=-5 b_{2} a_{2}^{2}+10 \sigma d_{1} a_{2}-4 \sigma^{2} f_{3}, \\
P_{4}=-5 b_{2} a_{2}^{4}+\left(10 \sigma b_{2} c_{2}-8 \sigma^{2} f_{3}\right) a_{2}^{2}-20 \sigma^{2} c_{2} d_{1} a_{2}+15 \sigma^{2} b_{2} c_{2}^{2} .
\end{gathered}
$$

Нарешті для поправки другого порядку у випадку симетричного каспу ми отримали наступний вираз:

$$
\begin{gathered}
\Delta_{L 2} T=\frac{\left(P_{5} \cdot \tilde{y}_{1}^{3}+3 \sigma^{2} C P_{6} \cdot \tilde{y}_{2}^{2}\right) x_{20}^{2}+\sigma P_{7} \cdot \tilde{y}_{1}^{2} \tilde{y}_{2} x_{20}+\sigma^{2} P_{8} \cdot \tilde{y}_{1} \tilde{y}_{2}^{2}+a_{1} a_{2} c^{2} \cdot \tilde{y}_{1}^{4}}{24 C^{2} E \sigma^{3}} \\
P_{5}=a_{1} a_{2}^{6}-3 \sigma a_{1} c_{2} a_{2}^{4}-8 \sigma^{3} h a_{2}^{3}-24 \sigma^{3} c_{2} g_{1} a_{2}^{2}+3 \sigma^{2} a_{1} c_{2}^{2} a_{2}^{2}+18 \sigma^{3} c_{1} c_{2}^{2} a_{2}-3 \sigma^{3} a_{1} c_{2}^{3}, \\
P_{6}=-12 \sigma a_{2}^{4}-a_{1} a_{2}^{3}+24 \sigma^{2} c_{2} a_{2}^{2}+9 \sigma c_{1} a_{2}^{2}-12 \sigma^{2} g_{1} a_{2}-12 \sigma^{3} c_{2}^{2}-4 \sigma^{3} h, \\
P_{7}=-a_{1} a_{2}^{5}-24 \sigma^{2} g_{1} a_{2}^{3}+3 \sigma a_{1} c_{2} a_{2}^{3}-28 \sigma^{3} h a_{2}^{2}+36 \sigma^{2} c_{1} c_{2} a_{2}^{2}- \\
\quad-60 \sigma^{3} c_{2} g_{1} a_{2}-9 \sigma^{2} a_{1} c_{2}^{2} a_{2}+27 \sigma^{3} c_{1} c_{2}^{2}, \\
P_{8}=12 \sigma a_{2}^{5}+4 a_{1} a_{2}^{4}-24 \sigma^{2} c_{2} a_{2}^{3}-9 \sigma c_{1} a_{2}^{3}-24 \sigma^{2} g_{1} a_{2}^{2}-9 \sigma a_{1} c_{2} a_{2}^{2}+ \\
+12 \sigma^{3} c_{2}^{2} a_{2}-20 \sigma^{3} h a_{2}+54 \sigma^{2} c_{1} c_{2} a_{2}-36 \sigma^{3} c_{2} g_{1} .
\end{gathered}
$$

Привертає увагу та обставина, що у виразах (17) і (18) у знаменнику стоїть величина $E$, яка може дорівнювати нулю. Як показано в [7], ця величина лише чисельним множником відрізняється від якобіана $J$ у нульовому наближенні. Отже, $E=0$ - це рівняння каустики у цьому наближенні. Коли джерело прямує до каустики, існування такого знаменника потребує - у загальній ситуації - більш ретельного аналізу граничного переходу, який ми плануємо провести в окремій роботі. Тут для ілюстрації дієздатності наведених формул ми обмежимося конкретним прикладом з наступного розділу.

\section{4. Приклад: джерело на осі лінзи Чанг-Рефсдала}

Ми хочемо за допомогою простого прикладу проілюструвати наскільки значення часу затримки, що даються фрормулою нульового наближення (16) можуть відхилятися від точних значень і який внесок в цю різницю дає у випадку симетричного каспу поправка (18). Для цього розглянемо так звану гравітаційну лінзу Чанг-Рефсдала, яка утворена точковою масою, розташованою у початку координат, та зовнішньою припливною гравітаційною дією, що характеризується параметром зсуву $\gamma[9,10]$. Відповідний лінзовий потенціал дається таким виразом

$$
\Psi=-\frac{\gamma}{2}\left(x_{1}^{2}-x_{2}^{2}\right)+\frac{1}{2} \ln \left(x_{1}^{2}+x_{2}^{2}\right)
$$

Векторне рівняння (1) приймає вигляд системи

$$
\begin{aligned}
& y_{1}=(1+\gamma) x_{1}-\frac{x_{1}}{x_{1}^{2}+x_{2}^{2}} \\
& y_{2}=(1-\gamma) x_{2}-\frac{x_{2}}{x_{1}^{2}+x_{2}^{2}}
\end{aligned}
$$

Вигляд критичної кривої і каустики для цієї системи добре відомі. Зокрема, зазначимо, що ці криві разом з потенціалом (19) $є$ симетричними відносно відбиття кожної з координатних осей. Каспи каустики знаходяться в точках її перетину з осями. На осі $y_{2}=0$ їм відповідають значення $y_{c 1}= \pm 2 \gamma / \sqrt{1-\gamma}$, а на осі ординат $-y_{c 2}= \pm 2 \gamma / \sqrt{1+\gamma}$.

Ми будемо розглядати окіл правого каспу і джерело, що розташоване на осі $y_{2}=0$. 3 рівнянь (21) і (20) знаходимо перший розв'язок $x_{2}^{(1)}=0, x_{1}^{(1)}=\frac{1}{2(1+\gamma)}\left[y_{1}+\sqrt{y_{1}^{2}+4(1+\gamma)}\right]$ (знак перед радикалом обрано так, щоби правому каспу відповідала права вершина критичної кривої $x_{c r 1}=1 / \sqrt{1-\gamma}$ ). Два інші розв'язки лежать на колі $x_{1}^{2}+x_{2}^{2}=1 /(1-\gamma): x_{1}^{(2,3)}=y_{1} / 2 \gamma, x_{2}^{(2,3)}= \pm \sqrt{\frac{1}{1-\gamma}-\frac{y_{1}^{2}}{4 \gamma^{2}}}$.

На рис. 1 зображено праву половину каустики і низку положень точкового джерела на осі $y_{2}=0$ як всередині каустики (кружечки), так і ззовні (трикутники); на рис. 2 показано половину критичної кривої і відповідні положення критичних зображень (темні символи - перше зображення, світлі - друге і третє; відповідність з положеннями джерела зручно встановлювати, рухаючись від каспа). Для визначеності ми поклали $\gamma=0.5$. 


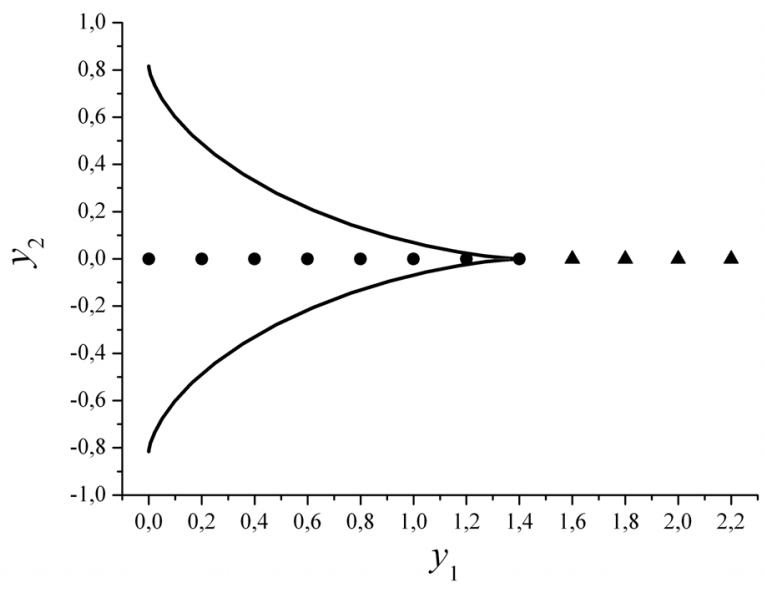

Рис. 1 Каустика і положення джерела на осі $y_{2}=0$

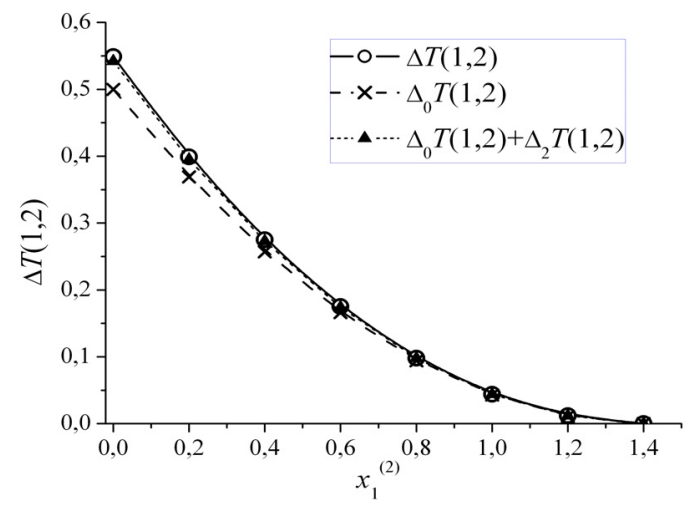

Рис. 3 Порівняння точного та наближених значень затримки першого зображення відносно другого для послідовних положень джерела, показаних на рис. 1

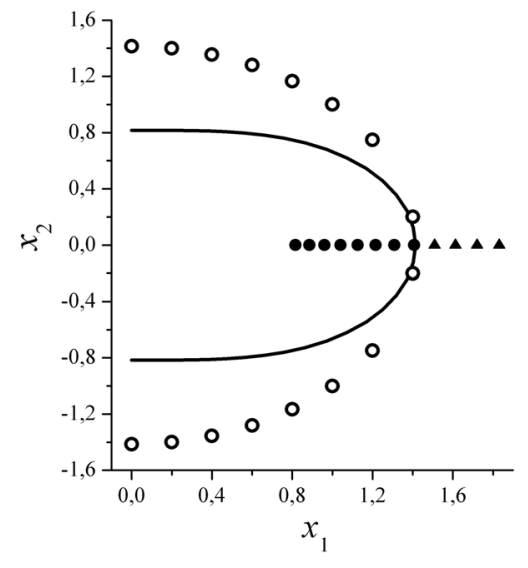

Рис. 2 Критична крива і положення зображень

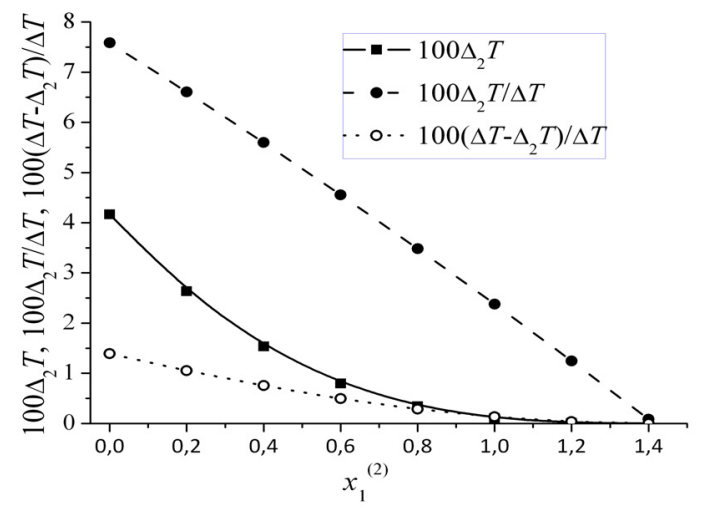

Рис. 4 Оцінка абсолютного значення поправки другого порядку (в днях), її відносного внеску в час затримки та залишкової похибки другого наближення (у відсотках)

Розглянемо відносну затримку першого зображення відносно другого при послідовних положеннях джерела $\Delta T(1,2)=\Delta_{L} T^{(1)}(\mathbf{y})-\Delta_{L} T^{(2)}(\mathbf{y})=\Delta_{N} T^{(1)}(\mathbf{y})-\Delta_{N} T^{(2)}(\mathbf{y})$. На рис. 3 цю величину, обраховану за формулою (6), подано в залежності від першої координати другого зображення $x_{1}^{(2)}(\mathbf{y})$ (кружечки, суцільна крива). Також на рис. 3 подано результати аналітичних розрахунків за фрормулою нульового наближення $\Delta_{0} T(1,2)=\Delta_{L 0} T^{(1)}(\mathbf{y})-\Delta_{L 0} T^{(2)}(\mathbf{y}) \quad$ (хрестики, штрихова) та з врахуванням поправки другого наближення (18) $\Delta_{0} T(1,2)+\Delta_{2} T(1,2)=\Delta_{L 0} T^{(1)}(\mathbf{y})-\Delta_{L 0} T^{(2)}(\mathbf{y})+\Delta_{L 2} T^{(1)}(\mathbf{y})-\Delta_{L 2} T^{(2)}(\mathbf{y})$ (трикутники, пунктир). Зауважимо, що поправка першого порядку тотожно дорівнює нулю внаслідок симетрії. Видно, що, принаймні у цьому прикладі, врахування поправки (18) дозволяє застосовувати аналітичну формулу не тільки в малому околі каспу, а і тоді, коли джерело знаходиться в центрі каустики.

На рис. 4 показано внесок поправки другого порядку $\Delta_{2} T(1,2)$. 3 огляду на те, що, як зазначено вище при обговоренні формули (5), коефіцієнт $\tau_{0}$ в середньому дорівнює приблизно 100 дням, величину $100 \cdot \Delta_{2} T$ можна вважати оцінкою абсолютного значення цієї поправки в днях (квадратики, суцільна крива). 3 іншого боку, більш показовим $є$ відносний внесок $\Delta_{2} T / \Delta T$, значення якого у відсотках показано темними кружечками і штриховою кривою. Також на цьому рисунку показана залишкова похибка другого наближення $\left(\Delta T-\Delta_{2} T\right) / \Delta T$ у відсотках (пунктир, світлі кружечки).

Підсумувати наш розгляд можна таким резюме. Отримана нами формула (17) дає поправку першого порядку до нульового наближення (16) для часу затримки критичних зображень, коли точкове джерело знаходиться в околі каспу (умови того, що у початку координат особливість типу зборки це $b_{1}=0$ і $C=c_{2} \sigma-a_{2}^{2} \neq 0$ ). Ця формула виведена для лінзового потенціалу загального виду, який допускає локальну апроксимацію виразом (10). Якщо він $є$ симетричним відносно заміни $y_{2} \rightarrow-y_{2}$ (симетричний касп), то поправка першого порядку тотожно дорівнює нулю. Для цього випадку ми знайшли поправку другого порядку (18). 3 розглянутого прикладу видно, що формула другого наближення з гарною точністю дає значення часу затримки не тільки в малому околі каспу, але навіть у центрі каустики.

Публікація містить результати досліджень, проведених при грантовій підтримці Держаного фонду фундаментальних досліджень за конкурсним проектом Ф64/45-2016. 
Список використаних джерел

1. Congdon A.B., Keeton C.R.,. Nordgren C.E. Identifying anomalies in gravitational lens time delays // Astrophys. J. - 2010. - Vol. $709 .-$ P. 552-571.

2. Koopmans L. V. E., Auger M., Barnabe M. et all. Strong gravitational lensing as a probe of gravity, dark-matter and super-massive black holes // arXiv:0902.3186.

3. Treu T., Marshall P. J., Cyr-Racine F. Y. et all. Dark energy with gravitational lens time delays // arXiv:1306.1272.

4. Suyu S. H., Treu T., Hilbert S. et all. Cosmology from gravitational lens time delays and Planck data // The Astrophys. J. Let. - 2014. - Vol. 788: L35 (6pp).

5. Александров О., Жданов В. Часова затримка критичних зображень точкового джерела поблизу каустики-складки гравітаційно-лінзової системи // Вісник Київ. ун-ту. Астрономія. - 2016. - № 53(1). - C. 6-11.

6. Congdon A.B., Keeton C.R., Nordgren C.E. Analytic relations for magnification and time delays in gravitational lenses with fold and cusp configurations // Mon. Not. Roy. Astron. Soc. - 2008. - Vol. 389. - P. 398-406.

7. Alexandrov A.N., Koval S.M., Zhdanov V.I. Gravitational lens equation: critical solutions and magnification near folds and cusps // Advances in Astronomy and Space Physics. - 2012. - Vol. 2, Iss. 2. - P. 184-187.

8. Александров О., Жданов В., Коваль С. Координати та підсилення критичних зображень в гравітаційно-лінзових системах: поправки другого порядку у околі симетричного каспу // Вісник Київ. ун-ту. Астрономія. - 2013. - 1(50). - C. 5-10.

9. Chang K., Refsdal S. Flux variations of QSO $0957+561$ A, B and image splitting by stars near the light path // Nature. - 1979. - Vol. $282 .-$ P. 561-564.

10. Schneider P., Ehlers J., Falco E. E. Gravitational Lenses. - Berlin: Springer, 1992.

Надійшла до редколегії 05.07.16

A. Alexandrov, Ph.D., sen. researcher

V. Zhdanov, Dr. Sci., Prof.

Astronomical Obseravtory of National Taras Shevchenko University of Kyiv

\section{TIME DELAY OF CRITICAL IMAGES IN THE VICINITY OF CUSP POINT OF GRAVITATIONAL-LENS SYSTEM}

We consider approximate analytical formulas for time-delays of critical images of a point source in the neighborhood of a cusp-caustic. We discuss zero, first and second approximations in powers of a parameter that defines the proximity of the source to the cusp. These formulas link the time delay with characteristics of the lens potential. The formula of zero approximation was obtained by Congdon, Keeton \& Nordgren (MNRAS, 2008). In case of a general lens potential we derived first order correction thereto. If the potential is symmetric with respect to the cusp axis, then this correction is identically equal to zero. For this case, we obtained second order correction. The relations found are illustrated by a simple model example.

А. Александров, канд. физ.-мат. наук., ст. наук. сотрудник

В. Жданов, д-р физ.-мат. наук, проф.

Астрономическая Обсерватория Киевского национального университета имени Тараса Шевченко

\section{ВРЕМЕННАЯ ЗАДЕРЖКА КРИТИЧЕСКИХ ИЗОБРАЖЕНИЙ ВБЛИЗИ КАСПОВОЙ ТОЧКИ ГРАВИТАЦИОННО-ЛИНЗОВОЙ СИСТЕМЫ}

Получены приближенные формулы для временной задержки критических изображений точечного источника вблизи касповой точки каустики. Мы обсуждаем формулы нулевого, первого и второго порядков по степеням параметра близости источника к каустике. Эти формулы связывают время задержки с характеристиками линзового потенциала. Формула для нулевого приближения была получена в роботе Конгдона, Китона и Нордгрена (MNRAS, 2008). Для обобщенного потенциала мы нашли к ней поправку первого порядка. В случае потенціала, симметричного относительно оси каспа, эта поправка обращается в ноль. Для такого случая мы получили поправку второго порядка. Найденные соотношения проиллюстрироованы на простому модельном примере.

УДК 523.942

О. Баран, інженер

М. Стоділка, д-р фіз.-мат. наук Астрономічна обсерваторія Львівського національного університету імені Івана Франка

\section{РОЗВИТОК КОНВЕКТИВНИХ СТРУКТУР У СОНЯЧНІЙ ФОТОСФЕРІ}

На основі моделей фотосферної конвекції, отриманих з використанням даних VTT шляхом розв'язку оберненої задачі нерівноважного переносу випромінювання, проведено дослідження розвитку конвективних структур у сонячній фотосфері. Для цього проаналізовано, як змінюються з часом варіації вертикальних швидкостей $і$ температури всередині грануляційних комірок. Досліджено особливості утворення та розпаду гранул в залежності від їх розміру, формування "дерев" з гранул, що фрагментуються.

Ключові слова: фотосферна конвекція, грануляційні комірки, фрагментація.

Вступ. Однією з характерних особливостей конвективних рухів на поверхні Сонця є наявність комірчастої структури різних просторово-часових масштабів [1]. Грануляція є найпомітнішою неоднорідністю сонячної фротосфрери. Конвективні потоки гарячого газу піднімаються до сонячної поверхні, утворюючи там яскраві комірки неправильної форми з розмірами порядку 1 Мм - гранули; з часом через швидке розширення газу та радіаційні втрати речовина в таких структурах охолоджується і гранули зникають, а появляються інші. В роботах [2, 3] досліджено різні механізми утворення і зникнення грануляційних комірок.

B роботі [4] на основі 3D аналізу (x, y, t) поля інтенсивності на грануляційних масштабах виявлено, що значна частка гранул у сонячній фотосфері об'єднується в утворення, названі авторами як Trees of Fragmenting Granules (TFG) - "дерева" з гранул, що фрагментуються. Ці структури беруть початок з однієї гранули, яка розпалася, та 3 часом налічують цілу ієрархію, яка продовжує фрагментуватися. Виявлено, що час життя таких грануляційних сімейств може сягати 8 год, що значно довше, ніж середній час життя окремої гранули - 10 хв. 3найдено, що 62\% поверхні займають гранули, які $є$ частиною довготривалих TFG з часом життя понад 1.5 год. Ці утворення мають схожість з мезогранулами і наводять на думку, що мезогрануляція повинна бути пов'язана з властивостями просторової та часової структури гранул. В роботі [5] підтвержено, що усереднення в часі довготривалих грануляційних утворень дає структури на мезогрануляційних масштабах; знайдено кореляцію між магнітною сіткою і просторовим розподілом "дерев". Зв'язок таких грануляційних сімейств, горизонтальних та вертикальних потоків і акустичних хвиль до- 